\title{
Spinal Cord Editor's Page April 2008
}

\section{Dear Spinal Cord reader,}

The review in this issue, by Lam et al., deals with ambulation outcome measures in spinal-cord-injured patients. The topic of outcome measures is interesting. Outcome measures are a measure of the result of a system, relative to the aim, and for spinal cord medicine the aims are manifold. They include: the overall aims of survival and prevention; the specific aims of preventing urinary infections or skin lesions; the aim to facilitate as much independence as possible; the aim to provide the best quality of life and the aim to achieve optimal ambulation. An outcome measure is used to measure the success of a system - in the case of spinal cord medicine, the success and possibilities of the comprehensive management. Often management focuses on output measures, which do not tell you about the success, but rather are a measure of activity. Publications have informed us how important it is to define good outcome measures, which can be used to determine the success of programs and whether improvement projects really result in improved outcomes.

Most participants in the care process handle outcome measures; for example, a physical therapy outcome measure is a test or scale administered and interpreted by physical therapists that has been shown to measure accurately a particular attribute of interest to patients and therapists and is expected to be influenced by intervention. It is a measure of change, the difference from one point in time (usually before an intervention) to another point in time (usually following an intervention). Similar techniques are used in occupational therapy, nursing, psychology, specialist medicine as well as most other parts of rehabilitation.

An outcome measure should be standardized, with explicit instructions for administration and scoring. The results obtained with a measure should be analysed to discover whether the change in health status recorded is directly attributable to the intervention. To make rational decisions about whether an intervention is of value, careful analysis of the cause of the outcome must be made.

How far have we come from the classical medical approach in which the doctor measured the outcome of his care in a personal, thoroughly subjective way and adapted his doing and thinking according to these impressions? The total bag of these individual data created what one could call 'experience', and this approach has, of course, not been without value if one looks at the progress made in the care of spinal-cord-injured patients during the last 50 years. Moreover, it is still common practice in most aspects of care and is used by almost all who deliver such care. Almost every review or committee report ends with the recommendation that a lot more research is needed: the paper by Lam et al., is a good example of such research.

Using measurements of outcome is without doubt more objective, and permits better comparison so is therefore a step towards evidence-based diagnosis and treatment.

This issue of Spinal Cord provides a clear picture of the multidisciplinary aspect of spinal cord medicine. Original contributions and case reports deal with pain, urological surgery, psychological evaluation, oncology and its surgery, pulmonary function testing, heart conduction, muscle atrophy and meningitis complications.

Functional electrical stimulation presented at the 2007 ISCoS annual meeting in Iceland by Ragnarsson and discussed in the editorial page of October 2007 is now printed in full in this issue.

Regularly authors ask advice before submitting a manuscript for review. Do not hesitate to do so or to contact us. Spinal cord is the journal of all of us and for all of us.

Enjoy reading

Spinal Cord (2008) 46, 245; doi:10.1038/sc.2008.28

JJ Wyndaele

Editor-in-chief

E-mail: spinalcord@uza.be 